Данные виды залога (рис.2) могут переквалифицироваться один в другой в связи со снижением или улучшением их качества. Для этого силами залогового контроля Банка на ежемесячной основе проводится залоговый мониторинг, включая выездные проверки на месторасположение предмета залога для оценки его качества и условий эксплуатации. Помимо этого, необходим правовой мониторинг принадлежности залога, способов его страхования и также ценовых параметров.

Уровень кредитоспособности клиента и банковские действия с лимитами, а в частности их закрытие, открытие и сокращение, напрямую взаимозависимы.

Для оценки кредитоспособности используют известные методики, которые подразумевают под собой рейтинговую оценку заёмщика на основе количественных показателей (финансовые показатели) и неколичественных (качественных). В качественным показателям как правило относят степень финансовой прозрачности заёмщика, кредитную историю с банками, позицию на рынке ведения бизнеса, опыт руководства организации, информацию о судебных скандалах и изменениях в составе собственников организации, состав консолидированной группы (если такова имеется) и на её основе риск вывода капитала за пределы базнеса.

В случае, если риск-метрики в рамках данных расчётов указывают на наибольшую вероятность дефолта заёмщика, в дело включаются инструменты управления кредитного портфеля, которые служат базой для установления индивидуальных лимитов заёмщиков.

Но прежде чем возникли все эти мероприятия по минимизации рисков, существовало множество общеизвестных кейсов, которые описаны в экономической литературе, а также в открытых информационных источниках и СМИ, когда крупные компании становились банкротами и запускали механизм колоссальной потери денег коммерческим банкам, которые всё то время до возникновения угрозы банкротства обслуживали данную организацию и финансировали её деятельность.

Вместо того, чтобы обращаться к данным кейсам, прежде всего необходимо за основу информационной базы взять существующую методологию распознавания и оценки вероятности возникновения того или иного риска, на основе которой и возникли мероприятия по минимизации.

$$
* * *
$$

1. Селина М. А. Банковские риски и методы их оценки (с рассмотрением примера на практике) [Текст] / М. А. Селина // IV Международная студенческая электронная научная конференция «Студенческий научный форум». - М.:, 2012. - С. 9-13.

2. РАЗВИТИЕ МЕТОДИКИ УПРАВЛЕНИЯ ФИНАНСОВЫМИ РИСКАМИ В УСЛОВИЯХ ЦИФРОВОЙ ЭКОНОМИКИ Наумова О.А., ТюГИН М.А. //УПРАВЛЕНИЕ БИЗНЕСОМ В ЦИФРОВОЙ ЭКОНОМИКЕ. СБОРНИК ТЕЗИСОВ ВЫСТУПЛЕНИЙ 3-еЙ МЕЖДУНАРОДНОЙ КОНФЕРЕНЦИИ. 2020. С. 264-268.

\title{
Информационно-аналитическая модель оценки инновационной активности отраслей АПК
}

ФГБОУ ВО «Чеченский государственный университет им. А.А. Кадырова» (Россия, Грозньй)

doi: 10.18411/trnio-12-2021-54

\section{Аннотация}

Инновационная активность регионального АПК представляется нам как деятельность субъектов в области фундаментальных и прикладных разработок, подготовки квалифицированных кадров, создания инновационной инфраструктуры и благоприятной среды, проработки и реализации схем программного финансирования инновационных проектов, а также коммерциализации инновационных предложений и проектов, создающих 
конкурентные преимущества и способствующую социально-экономическому росту и развитию региона.

Ключевые слова: инновационная активность, коммерциализации инноваций, информационно-аналитическая система.

\section{Abstract}

Innovative activity of the regional agro-industrial complex is presented to us as the activity of subjects in the field of fundamental and applied development, training of qualified personnel, creation of innovative infrastructure and favorable environment, elaboration and implementation of schemes for program financing of innovative projects, as well as commercialization of innovative proposals and projects that create competitive advantages and promote social benefits. - economic growth and development of the region.

Keywords: innovative activity, commercialization of innovations, information and analytical system.

Анализ основных отраслей и видов деятельности в разрезе административнотерриториальных зонам позволит обозначить более перспективные из них в плане инновационного развития.

С этой целью нами в работе предложена информационно-аналитическая система показателей, отражающих в количественном выражении уровень инновационной активности, и дальнейшего ранжирования отраслей АПК по уровню инновационного потенциала.

Для количественного обозначения уровня инновационного развития отраслей АПК ЧР, в рамках предлагаемой методики, необходимо использовать некоторый перечень цифробуквенных обозначений.

Интегральный индекс (показатель) инновационной активности отраслей АПК, состоящий из четырёх обобщенных блоков из совокупности частных показателей, с учетом коэффициента корреляции, отражает их влияние на объем инновационной продукции в ВВП $\left(I_{u a}\right)$.

Первый этап предлагаемой методики формирует и систематизирует оценочные факторы $\mathrm{P}\left(F_{i}\right)$ в разрезе 4-х блоков, характеризующих инновационную деятельность в данной отрасли АПК, степень коммерциализации инноваций, систему мер по стимулирвоанию инновационной деятельности, государственную политику в сфере управлениями инновациями (таблица 1).

На втором этапе определяются коэффициенты корреляции $K_{\kappa i}$, характеризующие степень влияния каждого $i$-ого фактора на результативный показатель $\left(P_{n}\right)$.

С этой целью необходимо провести корреляционный анализ факторов, систематизированных в таблице 1, в качестве ключевого из которых является удельный вес инновационной продукции в их общем объеме, а также показателя конечного результата $\left(P_{n}\right)$.

На третьем этапе для обеспечения сопоставимости числовых значений факторов используем возможности метода линейного масштабирования:

$$
Z_{i}=\frac{K_{k i}}{\max K_{k i}}
$$

где $\mathrm{Z}_{\mathrm{i}}$ - числовое значение факторов инновационной активности отраслей АПК;

махK $K_{\kappa}$, - эталонное (максимальное) числовое значение фактора $K_{\kappa i}$, в ряду $i$ анализируемых отраслей АПК Чеченской Республики.

На четвертом этапе рассчитываются числовые значения индексов инновационной активности, характеризующих инновационную деятельность $\left(I_{u a}\right)$; степень коммерциализации инновационных предложений и проектов $\left(I_{k n}\right)$; степень обеспеченности 
инновационными кадрами $\left(I_{o к}\right)$; государственная политика в сфере управлениями инновационной деятельностью $\left(I_{2 n}\right)$.

Числовые показатели частных индексов рассчитываются суммированием произведений нормированных факторов с учетом соответствующего коэффициента корреляции $K_{\kappa i}$.

На пятом этапе определяется комплексное значение инновационной активности отраслей АПК с помощью интегрального индекса $\left(\boldsymbol{I}_{\text {uap }}\right)$ :

$$
I_{\text {uap }}=I_{\text {ua }}+I_{o \kappa^{*}}+I_{\kappa n \bullet}+I_{z n}
$$

Предлагаемая нами информационно-аналитическая модель оценки инновационной активности отраслей регионального АПК представлена в таблице 1.

Таблица 1

Информационно-аналитическая модель оченки инновационной активности отраслей АПК

\begin{tabular}{|c|c|c|c|}
\hline & Наименование фактора & $\begin{array}{l}\text { Коэфф } \\
\text { ициент } \\
\text { коррел } \\
\text { яџฺии }\end{array}$ & $\begin{array}{l}\text { Частный } \\
\text { индекс } \\
\text { корреляциии }\end{array}$ \\
\hline 1. & Количество патентов, изобретений. в расчете на 1 тыс. чел. населения, ед. & $K_{\kappa l}$ & \multirow{3}{*}{$\begin{array}{l}\text { Активность } \\
\text { в создании } \\
\text { инноваций } \\
\left(\boldsymbol{I}_{\text {uа }}\right) \text {. }\end{array}$} \\
\hline 2. & Цитирование научных кадров региона (среднее значение) & $K_{K 2}$ & \\
\hline 3. & Количество международных РСТ-заявок (на 1 млн. чел), ед. & $K_{\kappa 3}$ & \\
\hline 4. & $\begin{array}{c}\text { Удельный вес предприятий, осущеествляющчих инноващчи, в числе } \\
\text { предприятий региона, \% }\end{array}$ & $K_{\kappa 4}$ & \multirow{4}{*}{$\begin{array}{c}\text { Активность } \\
\text { в } \\
\text { коммерцииали } \\
\text { зациии } \\
\text { инноваций } \boldsymbol{I}_{\text {кп }}\end{array}$} \\
\hline 5. & Удельный вес импорта технологий в общем объеме импорта, \%. & $K_{K 5}$ & \\
\hline 6. & Удельный вес экспорта технологий в объеме экспорта, \%. & $K_{\kappa 6}$ & \\
\hline 7. & $\begin{array}{c}\text { Удельный вес затрат бизнеса на НИОКР в общем объеме затрат на } \\
\text { НИОКР, \% }\end{array}$ & $K_{\kappa 7}$ & \\
\hline 8. & $\begin{array}{c}\text { Удельный вес кадров с учеными степенями в численности экономически } \\
\text { активного населения }\end{array}$ & $K_{\kappa 8}$ & \multirow{3}{*}{$\begin{array}{l}\text { Подготовка } \\
\text { инновационн } \\
\text { ых кадров } \boldsymbol{I}_{\text {ок }}\end{array}$} \\
\hline 9. & Численность научных организаиий на 10000 чел., ед. & $K_{K 9}$ & \\
\hline 10. & $\begin{array}{c}\text { Удельный вес работников, занятых исследованиями в общей численности } \\
\text { населения }\end{array}$ & $K_{\kappa 10}$ & \\
\hline 11. & $\begin{array}{c}\text { Удельный вес инновационных проектов, реализуемых институтами } \\
\text { развития республики, в числе проектов, реализуемых по России в цчелом, \% }\end{array}$ & $K_{\kappa l 1}$ & \multirow{3}{*}{$\begin{array}{c}\text { Активность } \\
\text { государствен } \\
\text { ной политики } \\
\text { в области } \\
\text { инновационн } \\
\text { ой } \\
\text { деятельност } \\
\text { и } \boldsymbol{I}_{\text {гn }}\end{array}$} \\
\hline 12. & $\begin{array}{c}\text { Удельный вес средств, выделяемых институтами развития республики на } \\
\text { реализацию проектов в регионе, в общем объеме средств, выделяемых } \\
\text { институтами развития на реализацию данного проекта в регионах } Р \Phi, \%\end{array}$ & $K_{\kappa 12}$ & \\
\hline 13. & $\begin{array}{c}\text { Численность федеральных институтов развития в совокупности } \\
\text { инновационных институтов, созданных в России, ед. }\end{array}$ & $K_{\kappa 13}$ & \\
\hline
\end{tabular}

Предлагаемая информационно-аналитическая модель оценки инновационной активности отраслей АПК может быть использована в работе ГКУ РАИИП в качестве диагностического инструмента, представляющего объективную ситуацию в АПК Чеченской Республики в плане инновационного развития.

Разработанная нами методика, возможно, не лишена отдельных недостатков, но бесспорны и следующие преимущества:

- широкий спектр используемых индикаторов, что повышает объективность результатов комплексной оценки инновационной активности отраслей регионального АПК;

- $\quad$ учет коэффициента влияния, дающая возможность сравнения с результатами инновационной деятельности отраслей АПК в сравнении с еe предпосылками;

- способность модели на «выходе» предоставить результаты комплексной оценки инновационной активности отраслей АПК, так и значения отдельных ее составляющих: активность в процессе создания инноваций, степень коммерциализации созданных инновационных проектов и продуктов, 
уровень обеспеченности инновационными кадрами, поддерживающие и стимулирующие мероприятия в области активизации инновационной деятельности государства;

- оценка факторов успеха инновационной деятельности в отраслях АПК отдельных регионов РФ и перенос их лучшей практики;

- $\quad$ акцентирование внимания федерального центра при распределении дотаций и субсидий на активность инновационной деятельности отраслей АПК.

Апробации предлагаемой модели с целью ранжирования отраслей АПК по инновационной активности была проведена на территории Чеченской Республики, и результаты расчетов приведены на рисунке 1 .

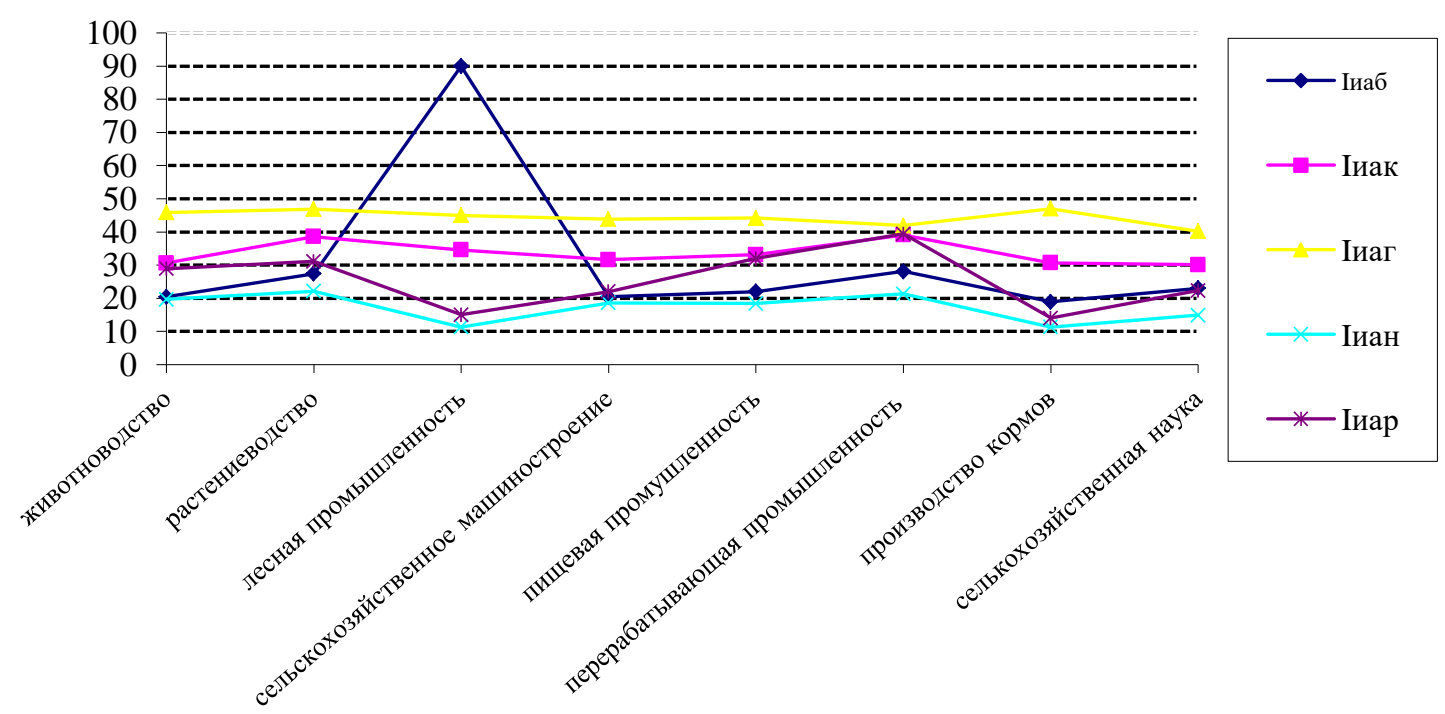

Рисунок 1. Распределение отраслей Ченченской Республики по уровню инновационной активности

Разработанная информационно-аналитическая модель оценки инновационной активности отраслей АПК позволит осуществить отбор отраслей АПК и оценить целесообразность формирования зон отраслевого развития (ЗОР) инновационного типа, путем поэтапного расчета социально-экономического положения, привлекательности отраслей АПК для потенциальных инвесторов и инновационной активности и потенциала в региональном АПК.

$$
* * *
$$

1. Алиева Л., Светлорусова Т. Инновационная система развития агропроизводственного рынка. АПК: экономика, управление, № 4, 2007, ст. 50-52

2. Гакаев Р. А. Роль природно-ресурсного потенциала в развитии экономики Чеченской Республики. Современные проблемы науки: сборник статей 1-й международной научно-практической конференции. Тамбов. 2008. С.40-43. В сборнике: Современные проблемы науки. Сборник статей 1-й международной научно-практической конференции. Тамбов. 2006. С. 45-50.

\section{Расумов В.Ш. \\ Специфика региональных программ социально-экономического развития и их структура}

ФГБОУ ВО «Чеченский государственный университет им. А.А. Кадырова» (Россия, Грозньй)

doi: $10.18411 /$ trnio-12-2021-55

\section{Аннотация}

Следует обозначить, что самой главной функцией органов исполнительной ветви власти на региональном уровне выступает формирование обоснованного с научной точки 